WIENER SLAVISTISCHES JAHRBUCH, Band 50/2004, 139-152

(C) 2005 by Österreichische Akademie der Wissenschaften, Wien

CORNELIA SOLDAT (BERLIN)

\title{
Die Erzählungen über Empfängnis und Geburt russischer Herrscher in der Stepennaja kniga carskogo rodoslovija und ihr Zusammenhang mit alten slavischen Fruchtbarkeitsriten
}

„One of the most poignant essays I have read in early Russian History concerns the untimely death in 1560 of Ivan IV's first wife, Anastasiia Romanovna", beschreibt die US-amerikanische Historikerin Nancy Shields Kollmann einen Artikel S. B. Veselovskijs aus dem Jahre $1945 .{ }^{1}$ Veselovskij diskutiert darin die Gründe für Anastasijas frühen Tod: hatten sich Adašev und der Beichtvater des Zaren, Sil'vestr, verschworen, sie zu töten? Oder die Bojaren? Oder jemand ganz anderes? Schließlich kommt Veselovskij zu dem Schluss:

„Анастасия умерла после медленного вгасания в том возрасте, когда женщина обыкновенно достагает полного расцвета сил. Об отравлении ее не может быть речи, да и сам Иван об этом не говорит, а в колдовство и чары мы, люди ХХ в., не верим. Остается предположить, что здоровье ее было подорвано ранным браком и частыми родами и окончательно расшатано постоянными поездками с мужем на богомолья и потехи. “2

Veselovskij zeigt, dass Anastasija sechsmal in acht Jahren niedergekommen war und ihren Mann und ihre Familie auf weitreichende Pilgerreisen jährlich oder zweimal jährlich begleitet hatte. Ivan selbst, so schloss Veselovskij, trieb sie in den Tod. ${ }^{3}$ Dieser Schluss passt zum Bild des rüden, jähzornigen und

\footnotetext{
${ }^{1}$ Nancy Shields Kollmann, Pilgrimage, Procession and Symbolic Space in Sixteenth-Century Russian Politics, in: Medieval Russian Culture, Vol. 2, ed. by Michael S. Flier and Daniel Rowland, Berkeley - Los Angeles London 1984 (= California Slavic Studies, 19), 163-181, hier: S. 163.

2 Wieder abgedruckt in S. B. Veselovskij, Bolezn' i smert' caricy Anastasii, in: ders., Issledovanija po istorii opričniny, Moskva 1963, 92-95, hier: S. 94.

„, Понимал ли Иван, что в преждевременной смерти его «юноцы» в значительной мере виноват он сам, мы не знаем, да это и несущественно, а важно то, что он, веря в колдовство, всю жизнь сохранял в душе эту воображаемую рану как оправдание его подозрительности и злобы к окружающим.“Veselovskij, Bolezn' i smert' caricy Anastasii, S. 94.
} 
rücksichtslosen Zaren Ivan, des „Schrecklichen“, der seinen eigenen Sohn im Zorn erschlug und der das Leben seiner Ehefrauen seinen sexuellen Begierden und seinen Jagdvergnügungen opferte. Schließlich ging Ivan sieben Ehen ein, und nur die letzte Ehefrau, Marija Nogaja, überlebte ihn.

Wie schon Kollmann hervorhebt, ${ }^{4}$ wird Veselovskijs Einschätzung der Reisen Ivans IV. als Vergnügungen, auf die er der Gesundheit seiner Frauen und Kinder ${ }^{5}$ zuliebe hätte verzichten können, der historischen Wirklichkeit und der kulturellen Praxis des 16. Jahrhunderts nicht gerecht. Während die Jagd im Moskovien des 16. Jahrhunderts noch der Nahrungsbeschaffung und weniger dem Zeitvertreib diente, war die Pilgerreise eine religiöse Pflicht. ${ }^{6}$ Insbesondere war sie eine Pflicht des Zaren, dem eine besondere Bindung zu Gott zugesprochen wurde und der als erster Mittler zwischen Gott und seinen Untertanen angesehen wurde. ${ }^{7}$ Mit der Konsolidierung des Moskoviter Staates im 15. Jahrhundert wurde die Pilgerreise immer mehr zur Staatsrepräsentation und zur Bindung des Heiligen an das moskovitische Land genutzt. Ein pilgernder Herrscher nimmt sein Land symbolisch auf dem Weg in Besitz, er lokalisiert das Zentrum und zeigt seine Verbindung mit dem Transzendenten, indem er das Land rituell zum Zeichen seiner Oberhoheit abschreitet. Die Pilgerreisen der Moskoviter Großfürsten hatten dementsprechend eine Bedeutung als Demonstrationen von Autorität, Demarkation eines heiligen Raumes und Manifestation der theoretischen Ordnung in ihrem Reich. ${ }^{8}$

Es ist dieser symbolische, durch den Weg geheiligte Raum, um den es Kollmann geht, und sie kann im weiteren Verlauf ihres Essays im Rahmen einer vergleichenden Chronikanalyse die Pilgerwege der Großfürsten von Ivan III. Vasil'evič über Vasilij III. Ivanovič bis zu Ivan IV. Vasil'evič nachvollziehen und in ihnen ein im Ablauf des Jahres festgelegtes Muster ausmachen, das die Großfürsten ständig wiederholten. Ich möchte im Folgenden diese Ergebnisse Kollmanns noch weiter führen und das Abschreiten des Landes durch den Herrscher als eine rituelle Aneignung verstanden wissen, die stark mit der männlichen Fruchtbarkeit des Herrschers verbunden ist. Dieses drückt sich im rituellen Abschreiten, das mit altslavischen Fruchtbarkeitsriten in Verbindung gebracht werden kann, aus. Indem der Herrscher auf Pilgerreise geht, sorgt er

\footnotetext{
${ }_{5}^{4}$ Kollmann, Pilgrimage, S. 164.

${ }^{5}$ Auf den Tod des Carevič Dmitrij im Jahre 1554 gehen weder Kollmann noch Veselovskij ein. Dmitrij ist auf einer Pilgerreise in einem Fluss ertrunken, manche sagen aufgrund der Unachtsamkeit des Zaren selbst, der ihn nicht richtig fest hielt.

${ }^{6}$ Vgl. einführend Konstantin G. Isupov, Pilgerfahrt, in: Norbert Franz (Hrsg.), Lexikon der russischen Kultur, Darmstadt 2002, 354-356.

${ }^{7}$ Vgl. hierzu Cornelia Soldat, Urbild und Abbild. Untersuchungen zu Herrschaft und Weltbild in Altrußland, 11.-16. Jh. (= Slavistische Beiträge, 402), München 2001, $218 \mathrm{ff}$.

${ }^{8}$ Kollmann, Pilgrimage, S. 165, zitiert Clifford Geertz, Centers, Kings, and Charisma. Reflections on the Symbolics of Power, in: Local Knowledge, New York 1983, 121-146, zu diesem Thema.
} 
in einem ganz archaischen Sinne auch für den materiellen Fortbestand seines Landes.

Das Verlassen der Residenzstadt auf der jeweiligen Pilgerreise, das Abschreiten der Wege durch den Zaren und seinen Hof und das Beten vor den Schreinen der russischen Heiligen und Klostergründer zeigen, dass die Pilgerreise Mittel der symbolischen Kommunikation war. Die Herrscher zeigten sich und demonstrierten ihre Macht und ihre Verbindung mit Gott. Es war deshalb ebenso wichtig, wenigstens die Moskoviter Kernlande durch Reisen abzudecken, um eine Konsolidierung und ein Zusammengehörigkeitsgefühl zu erreichen. Wie Kollmann zeigen konnte, diente Moskau für diese Reisen als Zentrum, die Großklöster als äußere Fixpunkte. ${ }^{9}$ Die Fahrt zu den Klöstern macht die Reisen in erster Linie zu Pilgerreisen.

Die Pilgerfahrt ist als kultureller Text im Sinne von Jan Assmann ein Zeichenkomplex, der für die Gesamtheit der Gesellschaft besondere normative und formative sinn- und identitätssichernde Verbindlichkeit besitzt. Sie strukturiert eine Sinnwelt, innerhalb derer man sich verständigt, produziert das $\mathrm{Be}$ wusstsein von Einheit, Zusammengehörigkeit und Eigenart und macht die Partizipierenden zu Angehörigen ihrer Gruppe. ${ }^{10}$ Assmann stellt dem sich wiederholenden Ritus den als sprachliche Äußerung verfassten Text ${ }^{11}$ gegenüber, der eine andere Form der Bewahrung und Archivierung voraussetzt. Der kulturelle Text des Ritus kann an die Gegebenheiten der nächsten Generation angepasst werden, am offenbarten Text wird dagegen ,kein Jota“ geändert. Beide Formen der Traditionsbewahrung sind kohärent, doch macht Assmann einen grundlegenden Wandel der Textstrukturen aus. Er impliziert, dass der kulturelle Text des Ritus zuerst da war und sich mit den Veränderungen der Speichermedien, der zeitlichen Zerdehnung der Kommunikationssituation mit der Einführung der Schrift, zum offenbarten Text gewandelt hat. ${ }^{12}$

Die Pilgerschaft ist im christlichen Verständnis eine Bußwallfahrt, ein Akt der tätigen Reue, der dann unternommen wird, wenn durch eine Verfehlung das Verhältnis zwischen dem Büßenden und Gott gestört worden ist. Sie

\footnotetext{
${ }^{9}$ Kollmann, Pilgrimage, S. 169. $149 \mathrm{f}$.

10 Jan Assmann, Religion und kulturelles Gedächtnis. Zehn Studien, München 2000,

${ }_{11}^{11}$ Assmann, Religion und kulturelles Gedächtnis, S. $126 \mathrm{f}$.

12 Assmann, Religion und kulturelles Gedächtnis, S. 150 f. Vgl. ebenda: „Der wesentlichste Unterschied zwischen mündlicher und schriftlicher Überlieferung solcher Mitteilungen oder ,kultureller Texte' besteht daher nicht im Medium und in der Technologie der Speicherung, sondern in der Institutionalisierungsform der zerdehnten Situation. Für mündliche Überlieferung gilt, dass die zerdehnte Situation wesentlich intensiverer Formung bedarf als in entwickelten Schriftkulturen und in der Regel einen rituellen Charakter annimmt. Fest und Ritus kennzeichnen die typische Form, wenn die schriftlosen Gesellschaften die zerdehnte Situation kultureller Texte institutionalisieren. Der Ritus sichert die Wiederaufnahme der Mitteilung, die kommunikative Präsenz des Textes und damit die rituelle Kohärenz der Kultur. Die frühen Schriftkulturen beruhen trotz der anwachsenden Masse des Geschriebenen noch in entscheidendem Umfang auf solcher rituellen Kohärenz."
} 
dient der öffentlichen Wiederherstellung dieses Verhältnisses. ${ }^{13}$ Die Pilgerfahrt des Herrschers muss in dieser christlichen Auffassung öffentlich stattfinden. Der Herrscher unternimmt sie stellvertretend für seine Untertanen. Der Wandel von der rituellen zur textuellen Kohärenz, den Assmann anmerkt, ${ }^{14}$ hat im Falle der christlichen Pilgerschaft bereits früh stattgefunden. Im altrussischen Ritus der Pilgerreise liegt der rituelle Text schon gewandelt vor, die Bevölkerung des Landes hat die Möglichkeit der stellvertretenden Teilnahme dadurch, dass sie den Tross des Herrschers am Wegesrand oder beim Einzug in eine Stadt begrüßt, dass sie ihn in der Etappe verköstigt und sich so seiner Fürbitte anempfiehlt. $^{15}$

Wenn der Zar an bestimmten Orten seiner Reise anhielt, handelte er als spiritueller Führer der Prozession. Er konsekrierte die Orte, die er abschritt, und machte sie zum Teil des einen heiligen Reiches. Prozessionen waren dynamische Komponenten des politischen Lebens. Dies zeigt sich nicht nur in ihrer Häufigkeit, sondern auch darin, dass neben dem Herrscher auch seine Familie und natürlich sein Hof, also auch die Vertreter der jeweiligen Kanzleien, prika$z y$, die Schreiber und sonstigen Hofbeamten, die für die Staatsführung unabdingbar waren, an den Prozessionen teilnahmen. So setzten der Moskoviter Herrscher und seine Herrschaftselite ihre theoretische und psychische Bindung zu Gott und der Welt physisch in Szene. Sie gaben ihren Zuschauern die Möglichkeit, sich mit dem herrschenden Wertesystem zu identifizieren und es zu internalisieren. ${ }^{16}$ Der so geschaffene Reichssymbolismus hing damit am Körper des Zaren und an seinem rituellen Abschreiten des Landes. Der Weg und der männliche Körper werden so zum inhärenten Bestandteil des Landes und seiner Segnung und erinnern an die im kulturellen Gedächtnis wachen heidnischen Fruchtbarkeitsrituale.

Wie Radoslav Katičić zeigen konnte, haben weißrussische, kroatische und russische Lieder zum Frühlings- und Osterumzug motivische Übereinstimmungen und lautliche Entsprechungen, die auf ein gemeinsames slavisches Erbe schließen lassen. Die Texte beziehen sich alle auf die gleichen Vorstellungen von einem Frucht bringenden Abschreiten eines Ackers durch eine mythische Person. Der rituelle Nachvollzug des Gehens auf dem Acker durch einen Festumzug wird mit dem Anregen von Fruchtbarkeit, im slavischen Lied durch den Reim hoditi - roditi 'gehen - gebären' symbolisiert, gleichgesetzt. ${ }^{17}$ Der Gang der mythischen Person bzw. der Umzug über die Felder wird in einem weiteren Schritt mit dem Frucht bringenden Lauf des Jahres gleichgesetzt. In

${ }^{13}$ B. N. Florja, Ispovednye formuly o vzaimootnošenijach cerkvi i gosudarstv $\mathrm{v}$ Rossii XVI-XVII vv., in: Odissej. 1992. Čelovek v istorii. Istorik i vremja, Moskva 1994, 204-214, S. 204.

14 Assmann, Religion und kulturelles Gedächtnis, S. 151

${ }^{15}$ Vgl. Assmann, Religion und kulturelles Gedächtnis, S. $130 \mathrm{f}$.

${ }^{16}$ Kollmann, Pilgrimage, S. 179.

${ }^{17}$ Radoslav Katičić, Hoditi - roditi. Spuren der Texte eines urslawischen Fruchtbarkeitsritus, Wiener Slavistisches Jahrbuch 33 (1987) 23-44, hier: S. 23 f. 
christlicher Zeit werden die Frucht bringenden Umzüge fortgesetzt und in den Zyklus des Kirchenjahres übernommen. Allerdings erhielten sie eine interpretatio christiana, indem sie mit unterschiedlichen Heiligen gleichgesetzt wurden, jedoch die alte Vorstellung von der Fruchtbarmachung beibehalten wurde. ${ }^{18}$ So spielt der Heilige Georg auf seinem weißen Pferd eine besondere Rolle in den slavischen Fruchtbarkeitsliedern. ${ }^{19}$ In Liedern und Umzügen wird der Gang der mythischen Person, die von weit her kommt, mit dem Bringen von Wachstum und Fruchtbarkeit in Verbindung gebracht. Der Weg führt über nasses Erdreich, die Schuhe der Person sind vom langen Gehen durchlöchert, sie watet im Wasser und versinkt im Schlamm. ${ }^{20}$ Die durchlöcherten Schuhe sind ein Symbol für die Durchlässigkeit der mit den Füßen penetrierten Erde und ihre Empfängnisbereitschaft. Hierin ist wohl auch der Grund zu sehen, warum die Lieder als weitere handelnde Personen Angeheiratete und keine Blutsverwandten haben. Die Fruchtbarkeitssymbolik des Umzugs kann so auf die eheliche Fruchtbarkeit umgedeutet werden. ${ }^{21}$ In einem weiteren Schritt wird in den Liedern der mythische Bräutigam mit einem Pferd identifiziert.

Pferde haben die menschliche mythologische Imagination wegen ihrer Möglichkeit, eine Reihe von miteinander verbundenen Phänomenen wie Macht, Reichtum, Göttlichkeit, Sexualität, Fliegen und die Spannung zwischen Zähmung und Freiheit zu symbolisieren, angeregt. Als frühestes Beispiel für die Assoziation des Pferdes mit Zähmung und Sexualität, eventuell sogar mit der Zähmung der Sexualität, gelten die Höhlenmalereien im französischen Lascaux, die auf etwa 30.000 v. Chr. datiert werden. Diese Verbindung von Pferd, Zähmung und Sexualität wurde zu einem dominanten Thema in den indoeuropäischen Kulturen. ${ }^{22}$ Pferdeopfer, vor allem Opfer von weißen, die Sonne oder das Göttliche symbolisierenden Pferden, ${ }^{23}$ hatten eine starke sexuelle Konnotation, waren mit Fruchtbarkeitskulten und -Riten verbunden und in der Antike sehr verbreitet. ${ }^{24}$ Vor allem der Schimmel galt in indoeuropäischen Kulturen im Allgemeinen als heiliges Tier, ${ }^{25}$ das in christlicher Zeit sowohl mit der Wiederkunft Christi in der Apokalypse (Off. 15) als auch mit den unterschiedlichs-

${ }_{18}^{18}$ Katičić, Hoditi-roditi, S. $24 \mathrm{f}$.
${ }^{19}$ Katičić, Hoditi - roditi, S. 23.
${ }^{20}$ Katičić, Hoditi - roditi, S. $26 \mathrm{f}$.
${ }^{21}$ Katičić, Hoditi - roditi, S. 31 . An anderer Stelle deutet Katičić dieses als verschlüsselte Inzestmotive: Radoslav Katičić, Weiteres zur Rekonstruktion der Texte eines urslavischen Fruchtbarkeitsritus, Wiener Slavistisches Jahrbuch 35 (1989) 57-98.

${ }^{22} \mathrm{Vgl}$. Wendy Doninger O'Flaherty, Horses, in: The Encyclopedia of Religion, vol. 6, ed. By Mircea Eliade, New York - London 1987, 463-468, hier: S. 463.

${ }^{23}$ O'Flaherty, Horses, S. 463 f.; vgl. V. V. Ivanov, Kon', in: Mify narodov mira, tom 1, Moskva 2 1991, 666.

${ }^{24}$ O'Flaherty, Horses, S. 463. Vgl. auch Viktor N. Toporov, Ideja svjatosti v drevnej Rusi. Vol'naja žertva kak podražanie Christu. „Skazanie o Borise i Glebe“, Russian Literature 25 (1989) 1-102, zum Zusammenhang zwischen Pferd, Fruchtbarkeit und dem Kult der Dioskuren, welcher seiner Meinung nach in den ostslavischen Kult der Heiligen Boris und Gleb eingegangen ist.

${ }^{25}$ O'Flaherty, Horses, S. 464. 
ten Heiligen assoziiert wurde. ${ }^{26}$ Hier ist der Grund dafür zu sehen, dass in ostslavischen Georgslegenden der Heilige Georg geradezu mit dem Schimmel identifiziert wird, wie Katičić bemerkt. ${ }^{27} \mathrm{Da}$ findet also in den von Katičić untersuchten Liedern der Fruchtbarkeits- und Osterumzüge eine Identifikation von christlichem Heiligen, dem Schimmel als altem Symbol des Göttlichen und indoeuropäischen Vorstellungen von der Frucht bringenden Sexualität des Pferdes statt. Hierbei ist es vor allen Dingen die Potenz des Hengstes, die mit der Frucht bringenden Sexualität des Pferdes konnotiert wird. ${ }^{28}$ Indoeuropäische Rituale und Zeremonien verbanden außerdem den Herrscher mit dem Rossopfer, indem der Hengst die Mächte des Kriegers, des Herrschers und des potenten Mannes symbolisierte. So wurden Sexualität und Prosperität zu einem Bestandteil von herrscherlichem Zeremoniell und Machtdarstellung. ${ }^{29}$ Dies ist der Punkt, an dem sich auch in Altrussland Fruchtbarkeitsriten und Herrscherzeremoniell treffen. Das rituelle Abschreiten der Felder im Zyklus der Jahreszeiten kann mit dem rituellen Abschreiten oder besser: Abreiten auf seinem bevorzugten Reittier, dem Schimmel, des russischen Herrschers auf der Pilgerfahrt verglichen werden. Diesen Zusammenhang möchte ich im Folgenden darlegen.

Das rituelle Abschreiten des Pilgerweges wird im Zug des Herrschers zu den Klöstern in sichtbare Verbindung mit dem rituellen Abschreiten des nassen Feldes in den jährlichen Fruchtbarkeitsumzügen gebracht. Der christliche Pilgerweg erhält eine heidnische Konnotation im Fruchtbarkeitskult, der ihn abschreitende bzw. abreitende Herrscher als spiritus rector der Reise hat ebenfalls Anteil an dieser Konnotation. In Gleichsetzung seines Körpers mit dem ihn tragenden Pferdekörper und seiner Männlichkeit mit der Potenz des Pferdes kann seine Reise das Land symbolisch befruchten. Sein Weg wird nicht nur segnend und heiligend, sondern auch fruchtbringend. Die befruchtende Beziehung zwischen Herrscherkörper und Land wird im rituellen Pilgerweg inszeniert und auf die Herrscherrolle zurückbezogen. Diese Funktion der Pilgerreise, die körperlich/fruchtbringende Anbindung des Herrschers an das Land durch das immer wiederkehrende Abschreiten von bestimmten Wegen, ist durchaus keine marginale. Zum einen kann man vom Weiterleben der heidnischen Fruchtbarkeitsriten im kulturellen Gedächtnis der Ostslaven ausgehen, ${ }^{30}$ zum

${ }^{26}$ O'Flaherty, Horses, S. 467.

${ }^{27}$ Katičić, Hoditi - roditi, S. 39, s. auch ebenda, FN 37. Zum Rossopfer in diesem Zusammenhang s. Katičić, Weiteres zur Rekonstruktion, S. 67 ff.

${ }^{28}$ Und die zu den aggressiven virilen Kulturen der Indoeuropäer geführt hat. S. O'Flaherty, Horses, S. 464.

${ }^{29}$ O'Flaherty, Horses, S. 464.

${ }^{30}$ Katičić macht an einer mythischen Erzählung aus der Ilias (14, 346-351), in der es um ein göttliches Paar geht, das die Erde durch sein Liebesspiel sich öffnen und Gras und anderes sprießen lässt, während der Tau auf den Pflanzen glitzert, auf den indogermanischen Ursprung dieser Fruchtbarkeitssymbolik aufmerksam. Vgl. Radoslav Katičić, Fragmente urslawischer sakraler Dichtung im bosnischen Epos, Wiener Slavistisches Jahrbuch 47 (2001) 73-84, hier S. 74: „Die bereits im slawischen und baltischen 
anderen zeigt sich die Richtigkeit der Annahme in den Erzählungen, die sich um die Empfängnis und Geburt der Großfürsten ranken, in denen eine Verbindung zwischen Weg und Fruchtbarmachung antizipiert wird.

Bereits in Kiever Zeit wurden die Großfürsten mit dem Charisma einer besonderen Beziehung zu Gott ausgestattet. Als Abbild Christi stand der Herrscher an der Spitze der weltlichen Ordnung, die durch das ikonische Prinzip von Urbild und Abbild die himmlische Herrschaft repräsentierte. ${ }^{31}$ Und so wie Christus durch ein Wunder - die Jungfrauengeburt mit vorausgegangener Verkündigung - geboren wurde, wurde den Großfürsten im 15. Jahrhundert eine wunderbare Geburt nachgesagt. ${ }^{32}$ Diese Wundererzählungen sind im Stufenbuch der Zarengenealogie, der Stepennaja kniga carskogo rodoslovija, aufgezeichnet, das die Funktion hatte, die christliche Herrschaft in der Rus' in 16 Stufen bis zum Zaren Ivan nachzuzeichnen und seine Herrschaft ebenso wie seine Familie christlich zu überhöhen. ${ }^{33}$

Die glückliche Geburt des Thronfolgers Vasilij Vasil'evič im Jahre 1415 wird zusammen mit dem Namen des Kindes dem Beichtvater des Zaren durch einen heiligen Eremiten mitgeteilt. Der Geistliche geht daraufhin zum Kreml' und findet Mutter und Kind wohlauf.

,Глава 2. Рожєніє вєликаго князя. Въ льто 6923 во врємя святаго и вєликаго чєтвєродєсятнаго поста, мЂсяца марта 15 дєнь, єгда приидє врємя, въ нє жє родитися таковому дєржавному отрочати, и тогда христолюбивая мати єго и вєликая княгиня Сооія нача вєльми нанємогати, яко и къ коньцу приближитися єй. Вєликій жє князь о сємъ скорбяшє вєльми. Бђ жє тогда нБкій старєць свять въ монастыри святаго Іоанна Прєдтєчи подъ Боромъ за Москвою рђкою, знаємъ жє бысть вєликому князю, єго жє вєльми любяшє. И посла къ нєму вєликій князь, да помолится о вєликой єго княгинђ, и будєтъ ли єй животъ. Онъ жє отвђша посланному къ нєму, сицє рєкъ: «Иди и рьцы вєликому князю, да и самъ помолися Господу богу и Прєчистой Єго Матєри и вєликому мучєнику Логину, понєжє той данъ бысть помощьникъ всєму роду вашєму о всђхъ, ихъ жє трєбуєтє благихъ. О своєй жє вєликой княгинъ скорби нє имђй: будєтъ здрава; въ сій жє вєчєръ родитъ сына, насльдника тєбђ» - єжє и бысть по прорєчєнію єго. Єгда жє родися, и въ той часъ свящєннику стоящу на молитвђ въ кЊліи своєй, ижє бысть духовникъ вєликому князю, живый въ монастыри Прєображєнія Господа Бога и

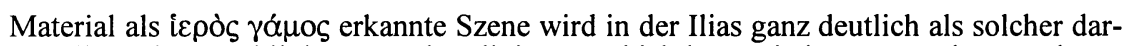
gestellt und von Philologen und Religionsgeschichtlern seit langem auch so wahrgenommen. Ein Element der Ausschmückung der epischen Erzählung, das beim Lesen der Ilias auf den ersten Blick eher frivol wirkt und im Kontext des Epos nicht viel mehr als eine galante Pikanterie darstellt, die durchaus zum Stil höfischen Umgangs passt, stammt, wie sich gezeigt hat, aus grauem Altertum und schildert einen hochheiligen mythischen Vorgang, der, wie man glaubte, wenn in richtige Worte gefasst, dem Ritus seine übernatürliche Macht verlieh, die Vorgänge in der alltäglichen äußeren Welt entscheidend zu beeinflussen."

${ }_{31}^{31}$ Soldat, Urbild und Abbild, S. 237 et passim.

${ }^{32} \mathrm{Vgl}$. dazu auch L. A. Sedov, Roždenie, in: Mify narodov mira, tom 2, Moskva 1992, 385-386, hier: S. 385: „Чудесное зачатие и р. тесно связаны с предметами, так или иначе символизирующими плодородие.“

${ }^{33}$ Einführend zur Stepennaja kniga s. N. N. Pokrovskij, Afanasij, in: Slovar' knižnikov i knižnosti Drevnej Rusi, Vyp. 2 (vtoraja polovina XIV-XVI v.), Čast' 1, Leningrad 1988, 73-79. 
Спаса нашєго Іисуса Христа, къ нєму жє пришєдъ нЊкто и удари во двєри кЊлія єго, рєкъ єму: «Иди, прєзвитєрє, и сотвори молитву княгинъ и новорожєнному отъ нєя младєнцу нарьцы имя Василій». Онъ жє скоро изыдє ис кђлія своєя и нє обрьтє никого жє посланного по нєго и удивися, яко скоро отидє звавый єго, и поидє съ монастыря къ вєликому князю. И срьтоша єго посланніи по нєго, яко да шєдъ дасть молитву вєликой княгинє и да нарєчєть имя рожєнному отъ нєя дЂтищу, Богомъ дарованному сыну вєликого князя Василія Дьмитрєєвича. Свящєнникъ жє воспроси єго, ашє онъ єсть прєждє проходилъ по нєго. И рєчє: «Нъсмь». И шєдъ потрєбныя таковаго врємєни молитвы совєрши и имя отрочати нарєчє Василій, тезоимєнитоє имя отьца єго, яко жє отъ Бога навъстися єму таковоє имєнованіє. И потомъ многу испытанію бывшу, кто єсть прєжє приходяй и и звавый, или кто пославый, и никто жє нє обрђтєся нигдђ жє: ни посланный, ни пославый. И сіє повђдано бысть и самому вєликому князю и вєликой княгинђ и многимъ людємъ, и вси дивишася и прославиша. “34

„KAPITEl 2. Die Geburt DES GROBFüRSTEN. Im Jahre 6923 zur Zeit der heiligen und großen vierzigtägigen Fasten, am 15. Tag des Monats März, als die Zeit kam, zu der aber dieses herrscherliche Kind geboren werden sollte, und da begann seine Christus liebende Mutter und Großfürstin Sof'ja sehr krank zu werden, als ob sich ihr Ende näherte. Der Großfürst aber war sehr bekümmert. Es gab jedoch damals einen gewissen heiligen Starec im Kloster des heiligen Johannes des Täufers am Waldrand und am Fluss Moskva, der dem Großfürsten bekannt war, den er sehr liebte. Und es sandte der Großfürst zu ihm, damit er für seine Großfürstin betete, auf dass sie am Leben bliebe. Der aber antwortete seinem Gesandten und sagte dies: ,Geh und sage dem Großfürsten, er soll selbst zu Gott dem Herrn und zu seiner allreinen Gottesmutter und zum Großmärtyrer Login beten, da es diesem gegeben ist, ein Helfer eures ganzen Geschlechtes in allem zu sein, von ihnen fordert Gutes. Über deine Großfürstin aber habe keine Bange: sie wird gesund werden; an diesem Abend noch gebiert sie einen Sohn, deinen Erben. Und es war nach seiner Prophezeiung. Als sie aber geboren hatte, stand zur gleichen Stunde ein Priester in seiner Zelle im Gebet, und der war der Beichtvater des Großfürsten, der im Kloster der Verklärung des Herren und unseres Retters Jesu Christi lebte, $\mathrm{zu}$ ihm aber kam jemand und klopfte an die Türe seiner Zelle und sagte ihm: ,Geh, Presbyter, und verrichte ein Gebet für die Großfürstin und den von ihr neu geborenen Knaben, der mit dem Namen Basilius gerufen wird.' Er aber ging schnell aus seiner Zelle und sah dort keinen Gesandten und wunderte sich, dass er so schnell gegangen war, nachdem er ihn gerufen hatte, und er ging aus dem Kloster zum Großfürsten. Und fragte, ob er nach ihm gesandt habe, dass er komme, ein Gebet für die Großfürstin zu sagen, und ob er den Namen des von ihr geborenen Kindes genannt habe, des gottgeschenkten Sohnes des Großfürsten Vasilij Dmitrievič. Der Priester aber fragte ihn, ob er es gewesen sei, der vorher bei ihm gewesen sei. Und er sagte: ,Ich war's nicht.' Und er ging, um das zu dieser Zeit geforderte Gebet zu verrichten und sprach den Namen aus, Vasilij sagte er, Namensvetter des Namens seines Vaters, ${ }^{35}$ wie ihm von Gott diese Namensgebung mitgeteilt worden war. Und danach gab es eine große Fragerei, wer es war, der da gekommen war und gerufen hatte, oder wer ihn gesandt hatte, und man fand niemanden, der gesandt worden wäre oder gesandt hätte. Und dies ist bestätigt worden sowohl vom Großfürsten und der Großfürstin als auch von vielen Menschen, und alle wunderten sich und lobten Gott.“

\footnotetext{
${ }^{34}$ PSRL 21,2, S. $457 \mathrm{f}$.

${ }^{35}$ Hier liegt eine Tautologie vor, die schwer ins Deutsche zu übertragen ist. Tezoimeniti bedeutet sowohl „Namensvetter“ als auch „Namenstag eines Mitglieds der Zarenfamilie“. Mit der Tautologie soll auf die Bedeutsamkeit des Namens für die gesamte Genealogie des Großfürsten hingewiesen werden. Auch Vladimir Svjatoslavič, der 1015 gestorbene Täufer der Rus', trug den Taufnamen Basilius.
} 
Die Geburt des Großfürsten beginnt mit der Bitte um ein Wunder. Als die Großfürstin bei der Geburt zu sterben droht, sendet der Großfürst einen Boten zu einem ihm bekannten Starcen. Dieser geht jedoch seinem Vorrecht als Starec nach und schickt eine Belehrung: Der Großfurst solle selbst zur Gottesmutter und seinem Schutzpatron, dem Großmärtyrer Login, beten. Dies ist keine direkte Abweisung der Bitte des Großfürsten und auch keine Anweisung, sich selbst zu helfen, damit ihm Gott helfe, sondern ein Verweis auf den Rangunterschied in der Beziehung zu Gott zwischen dem Starec und dem Großfürsten. Das Gebet des Großfürsten ist aufgrund seines Ranges und seiner Zugehörigkeit zu seinem Geschlecht wirksamer als das des Starec, der nur Mönch in einem Kloster ist. Aus diesem Grunde wird auf die Helferfunktion des Märtyrers Login für „всєму роду вашєму, dein ganzes Geschlecht“ hingewiesen. ${ }^{36}$ Nachdem er also den Großfürsten auf seine eigene besondere Verbindung zu Gott hingewiesen hat, wird der Starec selbst zum Boten Gottes und prophezeit die Geburt eines Sohnes und Erben, die lakonisch in einem Nebensatz angezeigt wird: Сгда жє родися, als sie aber geboren hatte. Der Starec handelt dem Großfürsten gegenüber gleich dem Engel, der der Gottesmutter die Geburt ihres Sohnes verkündigt (Lk 1). In einem zweiten Akt wird diese Geburt nicht nur der Familie, sondern der Welt in Gestalt eines Geistlichen, des Beichtvaters des Großfürsten, kundgetan. ${ }^{37}$ Ihm werden Geburt und Name des Sohnes des Großfürsten, Vasilij, angekündigt. Dieser Name verweist auf den Taufnamen des Sippengründers, Vladimir Svjatoslavičs, Basilius. ${ }^{38}$ Außerdem bedeutet er übersetzt „Herrscher“ und ist der offizielle Titel des byzantinischen Kaisers. Eine Parallele zum Weltherrschertum Christi (Christus Pantokrator) wird hier durch den Namen und den Aufbau der Geschichte noch einmal angedeutet.

\footnotetext{
${ }^{36}$ Gemeint wird hier Login sotnik sein, dessen Gedenktag am 16. Oktober gefeiert wird. Login war als Beamter Pontius Pilatus' Zeuge von Christi Kreuzestod und erkannte in dessen Leiden seine künftigen Wunder und ihn selbst als Sohn Gottes. Nachdem Login seinen Dienst quittiert hatte, ging er in die Wüste, um zu predigen, und wurde von den Juden an Pilatus verraten, der ihn daraufhin enthaupten ließ. Vgl. Žitija vsech svjatych, sost. Ioann Bucharev, Sankt Peterburg 1996, S. 588. Somit hat der Märtyrer zwar nichts mit Christi Geburt zu tun, wohl aber mit der Erkenntnis des Gottessohnes in der Stunde seines Todes. Hierin liegt auch sein Nutzen für die großfürstliche Familie, in der er wiederum für die Erkennbarkeit des Gottessohnes in seinem Abbild, dem Sohn des Großfürsten, sorgen soll. Die Funktion der Erwähnung Logins und seine Zuordnung zur großfürstlichen Familie ist also der Verweis auf die Christusabbildlichkeit des großfürstlichen Sohnes. Ansonsten hätte man eher die Gottesmutter allein als Fürbittende erwartet oder die Heiligen Boris und Gleb als Schutzpatrone der großfürstlichen Familie. Auch ein heiliger Großfürst wäre in dieser Situation denkbar gewesen, auf jeden Fall eher zu assoziieren als ein Märtyrer des 1. Jahrhunderts. Dieser ist vom Autor also bewusst in den Text aufgenommen worden, um auf die Gottessohnschaft hinzuweisen, denn eine andere Gemeinsamkeit ist nicht zu finden.

${ }^{37}$ Dies geschieht analog zur biblischen Erzählung von der Geburt Christi aus Lk 2, in der die Hirten, denen die Geburt verkündet wird, ebenfalls für die Welt stehen.

${ }^{38}$ Dieser ist außerdem als erster einer Reihe von altrussischen Fürsten zum Abbild Christi stilisiert worden, vgl. Soldat, Urbild und Abbild, S. 71-99.
} 
In der Erzählung geht der Geistliche, wie man ihm befohlen hat, nach Moskau und findet alles, wie es gesagt war. Auch hier ist die Parallele zur Darstellung des Christuskindes vor den Hirten (Lk 2,13 ff.) erkennbar. Im Palast des Großfürsten sorgt der Geistliche mit seiner Erzählung noch einmal für Wirbel, denn man findet den Boten nicht, der angeblich $\mathrm{zu}$ ihm geschickt worden ist. Dies macht deutlich, dass der Bote ein Engel Gottes war, der die Geburt verkündet hat. Im ersten Teil der Erzählung agierten noch menschliche Boten, im zweiten Teil nimmt der unsichtbare Bote wesentlich mehr Raum ein als vorher die sichtbaren. Es soll kein Zweifel aufkommen, dass es sich wirklich um einen Engel Gottes gehandelt hat, der Geburt und Namen des Sohnes mitgeteilt hat. Schließlich ermöglicht die Namensnennung eine weitere Korrelation mit Christus.

Die durch die Wundererzählung aufgebaute besondere Beziehung des Großfürsten zu Gott wird im Folgenden an die abgeschrittenen Pilgerwege gebunden. Dies geschah vornehmlich durch die Erwähnung einer der Empfängnis des Thronfolgers vorausgegangenen Pilgerreise des Herrscherpaares oder der Herrschergattin allein. Am Ende des 15. Jahrhunderts wurde die Empfängnis auf dem Pilgerweg von Sof'ja Palaiologa, der Gattin Ivans III. Vasil'evič, in einen von Isolde Thyrêt so genannten „Mythos vom gesegneten Schoß der Zarin“ umgedeutet. ${ }^{39}$ Die von Sof'ja in der Stepennaja kniga erzählte Geschichte weist darauf hin, dass sie während einer Pilgerfahrt, die sie ohne ihren Ehemann zum Kloster des heiligen Sergij von Radonež unternahm, durch Interzession des Heiligen mit dem künftigen Großfürsten Vasilij III. Ivanovič schwanger wurde. ${ }^{40}$

Die Erzählungen von der Geburt und Empfängnis der Großfürsten nehmen eine christliche Umdeutung der alten slavischen Vorstellungen von der InGang-Setzung von Fruchtbarkeit durch rituelles Abschreiten vor. Auch für das Herrscherpaar wird das Abschreiten des Landes zu einem Frucht bringenden Ereignis. Hier erfolgt die christliche Umdeutung jedoch zusätzlich noch durch eine Parallelisierung mit der Verkündigung und Geburt Christi, die den Akt der Empfängnis selbst in eine göttliche Sphäre entrückt und auf die Besonderheit des so empfangenen Kindes aufmerksam macht.

Vasilij III. Ivanovič, Sof'jas Sohn, bestieg 1504 den Moskauer Großfürstenthron, war jedoch 20 Jahre lang kinderlos mit Solomonija Saburova verheiratet. Seine Ehe war von Pilgerfahrten des Ehepaares oder Solomonijas allein u. a. zum Schrein des heiligen Sergij gekennzeichnet, um Nachkommen zu erbitten. Schließlich ließ sich Vasilij von Solomonija scheiden und heiratete Elena Glinskaja, die ihm, nachdem sie ihn zwei Jahre lang treu auf Pilgerfahrten begleitet hatte, durch Interzession des hl. Sergij einen Erben gebar, Ivan IV.,

${ }^{39}$ Isolde Thyrêt, "Blessed Is the Tsaritsa's Womb". The Myth of Miraculous Birth and Royal Motherhood in Muscovite Russia, Russian Review 53/3 (1994) 479-496.

${ }^{40}$ PSRL 21,2, S. 554 f.; vgl. Isolde Thyrêt, Between God and Tsar. Religious Symbolism and the Royal Women of Muscovite Russia, DeKalb 2001. 
den Schrecklichen. Hartmut Rüss zufolge war es auch diese Mutterschaft Elenas durch Interzession des Numinosen, die sie in ihrer Rolle als Regentin für ihren minderjährigen Sohn bestätigte. ${ }^{41}$

Die kinderlose Ehe Elena Glinskajas mit Vasilij Ivanovič wird in der Stepennaja kniga mit den kinderlosen Ehepaaren aus der Bibel, Abram und Sara, Elkanah und Hanna, Zacharias und Elisabeth, Joakim und Anna, verglichen. Schließlich wird auf die zahlreichen Pilgerfahrten hingewiesen, die der Großfürst unternommen hat, um ein Kind zu erhalten:

„Онъ жє, вєликодєржавный государь, нєумали подвига къ Богу въ молитвъ и нє усумнђся долгаго врємєни безчадствія и нє уны со прилєжаніємъ просити и нє прєста растощати богатьства нищимъ и во области царствія своєго объолжашє грады и чєстныя обитєлє, наипачє воздвизая чюдныя монастыря и святыя цєркви имєни Божію и Прєчистой Богородицы и всђмъ святымъ поставляя, и святыхъ иконъ воображєнія украшая, мьнизовъ жє, въ єго царствіи прєбывающихъ и отъ иныхъ странъ приходящихъ, любєзно упокоивая, всђхъ на молитву подвизая.““42

„Er aber, der großmächtige Herrscher, mühte sich ab in der Askese (podvig) für Gott, im Gebet und verzweifelte nicht in der langen Zeit der Kinderlosigkeit und hörte nicht auf, mit Eifer zu beten, und hörte nicht auf, seine Reichtümer unter den Armen zu verteilen und auf dem Gebiet seines Reiches Städte und reine Klöster zu gründen, er besuchte oft die von ihm gegründeten wundertätigen Klöster und heiligen Kirchen Gottes und der Allreinen Gottesmutter und aller Heiligen, er verschönte die Darstellungen der heiligen Ikonen, die Mönche aber, die in seinem Reich waren und aus anderen Ländern hergekommen waren, bewirtete er liebevoll, und alle leitete er zum Gebet an."

Die Geburt des Thronfolgers wird in einer Eulogie beschrieben und nun durch die Pilgerfahrt der Großfürstin erklärt:

„О дивство! Яко отъ таковыя царскія прєвєликія высоты въ каково пріидє самовольноє смирєномудріє, яко и по далєчєйшимь пустынямъ пђшу шєствовати єму своими царскими стопами и со своєю боголюбивою вєликою княгинєю Єлєною и со своими сигклиты. Да яко же вамъ бысть къ любовію влєкомъ, сицєву єму и помощьницо дарова Богъ, прємудростію и разумомъ во всємъ посльдуя самодєржавному богомудрому си супругу: всєгда бо на Бога возлагаху и вЂрою утвєржающєся и надєжєю вєсєляшєся. [...] И сихъ ради милосєрдый Богъ развєрзє союзь нєплодства єго и дарова єму родити сына, насльдника дєржавђ єго, подобна єму прємудростію и мужєствомъ и исправлєніємъ благочєстія."“43

„O Wunder! Wie er (Vasilij) von dieser großen herrscherlichen Größe hinabstieg zu freiwilliger, weiser Erniedrigung, wie er auch in die entlegensten Einöden zu Fuß ging, mit seinen herrscherlichen Schritten [sic!] und mit seiner gottliebenden Großfürstin Elena und mit seinem Gefolge. Ja, wie er selbst Gott in Glauben und Liebe zugetan war, genau so eine Helferin hatte ihm Gott gegeben, die in Weisheit und Verstand in allem ihrem selbstherrschenden gottweisen Ehemann folgte: [...] Und so zerriss der barmherzige Gott das Band der Unfruchtbarkeit, und es war ihm gegeben, einen Sohn zu gebären, den Erben seines Reiches, ihm gleich an Weisheit und Mut und in der Bestärkung der Frömmigkeit."

${ }^{41}$ Vgl. Hartmut Rüss, Elena Vasil'evna Glinskaja, in: Jahrbücher für Geschichte Osteuropas 19 (1971) 481-498, bes. S. $489 \mathrm{ff}$.

${ }^{42}$ PSRL 21,2, S. 606.

${ }^{43}$ PSRL 21,2, S. 606. 
In der Eulogie auf die Empfängnis des Sohnes und Erben wird diese nicht nur symbolisch an das Abschreiten des Pilgerweges geknüpft, sondern auch direkt lexikalisch. Die Worte „pešu šstvovati““ sind ein direkter Verweis auf das in den Frühlings- und Osterliedern gebrauchte Verb „hoditi“. Die Fruchtbarkeit des Großfürsten war also nicht so sehr an die fromme Tat der Pilgerreise, sondern eher an das archaische Gehen des Weges geknüpft. Dieses Motiv wird in der Stepennaja kniga im Folgenden wieder aufgenommen. Im Falle von Ivan IV. und Anastasija war es die Pilgerreise zum hl. Nikola von Pereslavl', die nach der Geburt dreier früh verstorbener Töchter die des Thronfolgers Dmitrij zur Folge hatte. ${ }^{44}$

Zudem konnte Daniel Kaiser in seiner Untersuchung der Riten und Bräuche, die bei den Hochzeiten Ivans IV. vollzogen wurden, nicht nur ihre Übereinstimmung mit den im Domostroj geschilderten Bräuchen feststellen, ${ }^{45}$ sondern auch auf besondere, bei den Zarenhochzeiten vollzogene Volksbräuche aufmerksam machen, die mit ehelicher Fruchtbarkeit und darüber hinaus mit dem urslavischen Ritus in Verbindung stehen, auch wenn Kaiser selbst sie als solche nicht erschließt. ${ }^{46}$

Zuerst wurde durch Ivan IV. eine Eskorte benannt, die ihn begleiten sollte, wenn er die Braut zu Hause abholte, und die das Paar nach der kirchlichen Trauung in die Zarenquartiere führte, wo die Ehe vollzogen werden sollte. ${ }^{47}$ Dieser Zug des herrscherlichen Bräutigams zu seiner Braut erinnert an die von Katičić erwähnten rituellen Fruchtbarkeitsumzüge auf den Feldern, in denen eine mythische Person zu einer Frau kommt. Hierfür spricht auch das im Domostroj und in den Erzählungen von den Hochzeiten Ivans IV. erwähnte Pferd, auf dem der Bräutigam zu seiner Braut ritt. ${ }^{48}$ Schließlich wurde die herrscherliche Braut mit Hopfen und Goldstücken besprengt, ${ }^{49}$ was an den glitzernden Tau im Mythos erinnert. Im Ritt des Zaren zu seiner Braut wiederholt sich bei den Hochzeitsbräuchen die mythische Ankunft des fruchtbringenden Mannes/ Pferdes bei seiner Partnerin. Das Besprengen der Braut mit glitzernden Goldstücken verweist auf das glitzernde Wasser im alten Fruchtbarkeitsmythos und auf den Frucht bringenden Vollzug der Ehe. Dieser ist konkret für die Nachkommen des Ehepaares verantwortlich, im übertragenen Sinne jedoch für die Prosperität des gesamten Reiches.

Noch für die späten 1580er Jahre berichtet der englische Gesandte Giles Fletcher von der Sitte der Zarin Irina Godunova, auf Pilgerfahrten zu gehen

\footnotetext{
${ }^{44}$ PSRL 21,2, S. 651-652; Thyrêt, Between God and Tsar, S. 55.

${ }^{45}$ Daniel H. Kaiser, Symbol and Ritual in the Marriages of Ivan IV, Russian History / Histoire Russe 14 (1987) 248-262. Vgl. auch Ukaz svadebnomu cinu, in: Domostroj. Sil'vestrovskago izvoda, Kiev 1992 (Reprint 2-oj izdanii Sankt Petersburg 1902), 7274.

${ }^{46}$ Kaiser, Symbol and Ritual, S. $260 \mathrm{f}$.

${ }^{47}$ Kaiser, Symbol and Ritual, S. $256 \mathrm{f}$.

${ }^{48}$ Kaiser, Symbol and Ritual, S. $257+260$.

${ }^{49}$ Kaiser, Symbol and Ritual, S. 258.
} 
und um einen Sohn zu bitten. Als Protestant beurteilt Fletcher den Aufwand, mit dem diese Pilgerfahrten betrieben wurden, sehr abschätzig, wie auch die Implikation, die die Interzession des heiligen Sergij mit sich bringt:

"The empress that now is hath many vowes to Saint Sergius, that is patron there, to entreat him to make her fruitful, als having no children by the emperor her husband. Lightly every year she goeth on pilgrimage to him from Moscow on foot, about eighty English miles with five or six thousand women attending upon her, all in blue liveries, and four thousand soldiers for her guard. But Saint Sergius hath not yet heard her prayers, though (they say) he hath a special gift and faculty that way." 50

Die Geburt eines Thronerben und die Pilgerreise, von Fletcher als vermeintlich Aufgeklärtem so abschätzig in Verbindung gebracht, wurden im Kontext des 16. Jahrhundert in Altrussland tatsächlich als miteinander verbunden betrachtet. Die Möglichkeit, dass ein Heiliger für Nachwuchs sorgt, wurde als real empfunden, wie die Erzählungen der Stepennaja kniga deutlich machen. Im 15. Jahrhundert stellte man die Geburt des Thronfolgers parallel zur Geburt Christi dar, am Ende dieses Jahrhunderts wurde auch seine Empfängnis so dargestellt. Neben dieser christlichen Überhöhung steht jedoch die Ausnutzung der im kulturellen Gedächtnis vorhandenen Fruchtbarkeitsriten, die durch ein Abschreiten feuchter Felder, eine Gleichsetzung von Frucht bringender mythischer Person und Pferd/Schimmel und von der zeugenden Vereinigung eines Paares gekennzeichnet sind und die selbst bei der Verehelichung des Zaren eine große Rolle spielten. Das Abschreiten des rituellen Pilgerwegs durch den Zaren wird damit nicht nur zu einem Prozess der Inkorporation des abgeschrittenen Landes durch den Herrscher, sondern auch zum Prozess von Frucht, Reichtum, schließlich Heil, weil der Ritus den Weg und das Land heiligt. In dieser Deutung liegt es wiederum nahe, den Pilgerweg auf die Zeugung der eigenen Nachkommen hin umzudeuten, wiederholt er doch sinngemäß die fruchtbarmachenden (Volks-)Rituale der Hochzeit, wie sie z. B. im Domostroj geschildert werden. Die Pilgerschaft erhält somit im kollektiven Gedächtnis eine doppelte Konnotation. Zum einen ist sie eine gottgefällige christliche Tat, zum anderen wird sie mit dem Abschreiten des Feldes mit dem Fruchtbarkeitsritus konnotiert. Es ist diese letztere Konnotation, die in die Erzählungen von der wunderbaren Empfängnis der Thronerben durch eine Pilgerreise im 16. Jahrhundert eingeht, sie prägt und sie zum Teil des kulturellen Gedächtnisses werden lässt, das von Ausländern belächelt, von Russen selbst jedoch als Wahrheit anerkannt wird.

In diesem Licht bekommt die Ursache des frühen Todes der Zarin Anastasia, hervorgerufen durch zu viele Geburten und Pilgerfahrten, eine neue kulturelle Dimension, in der sich Geburten und Pilgerfahrten und der Fortbestand des Reiches miteinander verbinden. Die Pilgerfahrten des Herrscherpaares wa-

${ }^{50}$ Giles Fletcher, Of the Russe Commonwealth, in: Rude and Barbarous Kingdom. Russia in the Accounts of Sixteenth-Century English Voyagers, ed. By Lloyd E. Berry and Robert O. Crummey, Madison-Milwaukee-London 1968, 109-248, hier: S. 117 f. 
ren notwendig zur mythischen Erzeugung von Reichtum und zur identifizierenden Integration der besuchten Landstriche in das Moskoviter Reich. Auf der anderen Seite waren sie aufgrund ihrer mythisch-fruchtbringenden Wirkung überhaupt erst die Vorbedingung für die Empfängnis der Thronerben und damit für den Fortbestand der Herrscherdynastie und das damit angestrebte prosperierende Fortbestehen des Reiches. 